\title{
Toxic effects of iron oxide nanoparticles on human umbilical vein endothelial cells
}

This article was published in the following Dove Press journal:

International Journal of Nanomedicine

25 May 2010

Number of times this article has been viewed

\author{
Xinying $\mathrm{Wu}^{\prime}$ \\ Yanbin Tan' \\ Hui Mao ${ }^{2}$ \\ Minming Zhang' \\ 'Department of Radiology, Second \\ Affiliated Hospital, Zhejiang University \\ School of Medicine, Hangzhou, \\ Zhejiang, China; ${ }^{2}$ Department of \\ Radiology, Center for Systems \\ Imaging, Emory University School of \\ Medicine, Atlanta, Georgia, USA
}

\begin{abstract}
Iron oxide nanoparticles (IONPs) have been employed for hyperthermia treatments, stem cell therapies, cell labeling, and imaging modalities. The biocompatibility and cytotoxic effects of iron oxide nanoparticles when used in biomedical applications, however, are an ongoing concern. Endothelial cells have a critical role in this research dealing with tumors, cardiovascular disease and inflammation. However, there is little information dealing with the biologic effects of IONPs on the endothelial cell. This paper deals with the influence of dextran and citric acid coated IONPs on the behavior and function of human umbilical vein endothelial cells (HUVECs). After exposing endothelial cells to IONPs, dose-dependent effects on HUVECs viability, cytoskeleton and function were determined. Both citric acid and dextran coated particles appeared to be largely internalized by HUVECs through endocytosis and contribute to eventual cell death possibly by apoptosis. Cytoskeletal structures were greatly disrupted, as evidenced by diminished vinculin spots, and disorganized actin fiber and tubulin networks. The capacity of HUVECs to form a vascular network on Matrigel ${ }^{\mathrm{TM}}$ diminished after exposure to IONPs. Cell migration/invasion were inhibited significantly even at very low iron concentrations $(0.1 \mathrm{mM})$. The results of this study indicate the great importance of thoroughly understanding nanoparticle-cell interactions, and the potential to exploit this understanding in tumor therapy applications involving IONPs as thermo/chemoembolization agents.
\end{abstract}

Keywords: iron oxide nanoparticles, cytotoxicity, in vitro test, cytoskeleton, human umbilical vein endothelial cell

\section{Introduction}

Magnetic iron oxide nanoparticles are a promising tool for cell tracking, cell targeted drug delivery, transfection and diagnostics agents. ${ }^{1-4}$ In addition, there are potential applications in magnetic intracellular/interstitial hyperthermia..$^{5-7}$ To date, a wide variety of magnetic nanoparticles have been produced, differing in size and type of coating material, including dextran, citrate, starch, albumin, silicones and polyethylene glycol (PEG). ${ }^{8,9}$ Particle size and surface modification lead to different responses in terms of cell nonspecific or receptor-mediated uptake to iron oxide nanoparticles IONPs. ${ }^{10-12}$ It is well known that IONPs can be taken up into the reticuloendothelial system (RES) by endocytosis or phagocytosis. IONPs are also taken up by phagocytic cells such as monocytes, macrophages, and oligodendroglial cells. As discovered in research concerning atherosclerosis and stem cell labeling, IONPs can also be found in the endothelial cells. ${ }^{13,14}$

Previous studies have reported the cytotoxic effects of IONPs on the cytoskeleton of growing neurons and human melanoma cells. ${ }^{15,16}$ Although there are numerous
Correspondence: Minming Zhang Department of Radiology, The Second Affiliated Hospital, Zhejiang University School of Medicine, 88 Jiefang Road, Hangzhou, Zhejiang 310009, China Tel $+8657 \mid 87315255$

Fax +8657187315255

Email cjr.zhangminming@vip.163.com 
reports concerning the use of IONPs labeled endothelial progenitor/stem cells for imaging techniques and the induction of hyperthermia by intravascular administration of ferromagnetic particles, there is little information in concerning the effect of this loading on endothelial cell behavior and function. ${ }^{17-20}$ Angiogenesis is a hallmark of cancer, ischemic and inflammatory diseases and the endothelial cell is a key cell labeled with IONP in research on tumor growth/metastasis and atherosclerosis. Thus, it is essential that the biological effects of IONPs on the endothelial cell be assessed.

Since bare IONPs are highly unstable in saline solutions, forming optically visible aggregates, we chose dextran and citric acid coated IONPs to observe the interaction of IONPs on human umbilical vein endothelial cells (HUVECs). ${ }^{21}$ Both coating materials are commonly used for stabilizing and functionalizing IONPs for biomedical applications. ${ }^{22,23}$ The aim of this study is to understand the in vitro interactions between nanoparticles and endothelial cells in terms of particle uptake, and the effects on cell proliferation, the cytoskeleton (F-actin, vinculin and tubulin), cell differentiation, cell migration, and invasion. This information will inform future research on endothelial cell-labeling and cancer-related hyperthermia treatments.

\section{Materials and methods Nanoparticle synthesis}

Magnetite IONPs were prepared in situ by co-precipitation from an iron-dextran or citric acid solution according to standard co-precipitation techniques. Briefly, 2 starting solutions were made by adding $0.60 \mathrm{~g}$ of $\mathrm{FeCl}_{3} \cdot 6 \mathrm{H}_{2} \mathrm{O}$ to $2 \mathrm{~mL}$ of deionized (DI) water and, separately, adding $0.21 \mathrm{~g}$ of FeCl$_{2} \cdot 4 \mathrm{H}_{2} \mathrm{O}$ to $0.5 \mathrm{~mL}$ of a $2 \mathrm{M}$ solution of $\mathrm{HCl}$. These solutions were then added to $10 \mathrm{~mL}$ of DI water with $0.372 \mathrm{~g}$ citric acid or $1 \mathrm{~g}$ dextran with vigorous stirring. The resulting solution mixture was titrated with $2 \mathrm{~mL}$ of a $5 \mathrm{M}$ sodium hydroxide with vigorous stirring for 30 minutes during which a black precipitate formed, indicating the formation of a $\mathrm{Fe}_{3} \mathrm{O}_{4}$ nanoparticle colloidal suspension. This solution was heated to $80^{\circ} \mathrm{C}$ and kept for 2 hours and then centrifuged at $900 \times \mathrm{g}$ for 5 minutes. The supernatant was then removed before the nanoparticles were dispersed in DI water. This washing process was repeated 4 additional times and the centrifugate was finally dispersed in $10 \mathrm{~mL}$ of DI water.

\section{Nanoparticle characterization}

The average particle size and distribution were determined using transmission electronic microscopy (TEM) (JEOL, Tokyo, Japan). The aqueous dispersion of the particles was drop cast onto a carbon coated copper grid, which was subsequently air dried at room temperature before loading into the microscope. The lyophilized IONPs were ground with KBr for FT-IR measurement by a Nicolet 6700 Fourier transformed infrared spectrometer (Thermo, Waltham, MA, USA). Samples of blank iron oxide particles prepared in parallel, under the same conditions although without coating materials were utilized as a control.

\section{Cell culture}

HUVECs were purchased from Cascade Biologics (Portland, OR, USA) and cultured in Medium 200 containing: $10 \%$ fetal bovine serum; 1\% L-glutamin (200 mM); 1\% penicillin $(100 \mathrm{U} / \mathrm{mL})$; and $1 \%$ streptomycin $(100 \mu \mathrm{g} / \mathrm{mL})$; supplemented with Low Serum Growth Supplement (LSGS) in a $5 \% \mathrm{CO}_{2}$ incubator at $100 \%$ humidity and a temperature of $37^{\circ} \mathrm{C}$. The cells were regularly monitored using an inverted light microscope, and the culture medium was changed 3 times a week. To deliver IONPs into HUVECs, cells were plated at a density of approximately $2 \times 104$ cells/mL into 6 -well plates or seeded on glass coverslips, which were then allowed to adhere overnight. The following day, cells were washed and incubated in complete medium, supplemented with IONPs at different concentrations, for 1 hour (iron concentration was confirmed by atomic absorption spectroscopy). All control cells were cultured in the absence of any particles.

\section{In vitro cell viability assay}

The MTT (3-(4,5-dimethylthiazol-2-yl)-2,5-diphenyltetrazolium bromide, a tetrazole) assay is very often used to evaluate cell proliferation and the viability for biomaterial toxicity. ${ }^{24}$ The MTT assay relies on reading the absorbance of formazan and might be affected by the adhesion or nonspecific adhesion of IONPs. Live cells have intracellular esterases that convert nonfluorescent, cell-permeable, calcein acetoxymethyl ester (calcein AM) to the intensely fluorescent green calcein which is retained within the cells. The toxicity level of IONPs was assessed by the calcein AM assay. The iron concentration to be tested was from $0.03-20 \mathrm{mM}$ (as given in the literature). ${ }^{15,25,26}$ In our experiment iron concentrations from $0.08-20 \mathrm{mM}$ were adjusted to test the cytotoxicity of the IONPs. HUVEC cells were seeded at a density of $1 \times 104$ cells/well in a 96 -well tissue culture plate (BD Biosciences, Franklin Lakes, NJ, USA) and incubated overnight. Following starvation with $1 \%$ serum in medium for 24 hours, cells were treated with IONPs at a concentration from 0.1 to $20 \mathrm{mM}$ for 1, 6 and 24 hours, in quadruplets, in the complete medium. Control cells were used without particle 
treatment. At the end of each exposure, the medium was removed and the cells were washed 3 times with phosphate buffered saline (PBS). The green calcein was measured at 494/517 nm using a microplate reader. All experiments were performed 3 times and in quadruplets, with the average of all the experiments being shown as a cell-viability percentage in comparison with the control cells, which were considered as $100 \%$ viable.

\section{Prussian blue staining of intracellular IONPs}

For Prussian blue staining, the cells were incubated with IONPs at concentrations of 0.1 and $1 \mathrm{mM}$ for 1 hour. After incubation, the culture medium was removed. The adherent cells were washed 3 times with PBS (0.1 M, pH 7.4), trypsinized, and centrifuged for 10 minutes at $1500 \mathrm{rpm}$. The number of cells was determined using a Neubauer counting chamber. After growing overnight in six-well plates with glass coverslips, HUVECs were washed 3 times with PBS, and subsequently fixed with 4\% paraformaldehyde/PBS. Following this the fixed cells were incubated with $10 \%$ potassium ferrocyanide for 5 minutes, with $10 \%$ potassium ferrocyanide in $20 \%$ hydrochloric acid for 30 minutes, and counterstained with nuclear fast red.

\section{Visualization of intracellular IONPs by TEM}

For cell samples, the cells were seeded into six-well plates and grown overnight. One hour after exposure to IONPs of 0.1 and $1 \mathrm{mM}$, cells were collected and fixed in an aqueous solution of $2.5 \%$ glutaraldehyde in PBS ( $\mathrm{pH} 7.0$ ) for more than 4 hours before being washed 3 times in the phosphate buffer; they were then postfixed with $1 \%$ osmium tetroxide in phosphate buffer ( $\mathrm{pH}$ 7.0) for 1 hour. Following this they were again washed three times in the phosphate buffer. The samples were dehydrated by a graded series of ethanol $(50 \%, 70 \%, 80 \%, 90 \%, 95 \%$ and $100 \%)$ for approximately 15-20 minutes for each step, and then transferred to absolute acetone for 20 minutes. Later, the samples were infiltrated with a 1:1 mixture of absolute acetone and the final Spurr resin mixture for 1 hour at room temperature before being transferred to a 1:3 mixture of absolute acetone and the final resin mixture for 3 hours, and then to the Spurr resin mixture overnight. Samples were placed in capsules containing embedding medium and heated at $70^{\circ} \mathrm{C}$ for about 9 hours, following this they were stained with uranyl acetate and alkaline lead citrate for 15 minutes each, before being observed using a TEM (JEOL, Tokyo, Japan).

\section{Fluorescent cytoskeleton and focal adhesion kinase (FAK) observation}

Cells were seeded on the coverslips and grown overnight. After 1 hour culture with IONPs under the conditions described previously, cells were washed with PBS and fixed in $4 \%$ paraformaldehyde/PBS at room temperature for 15 minutes. After this they were washed again with PBS and permeated with Triton X-100/PBS for 5 minutes before finally being incubated in 1\% BSA/PBS for 30 minutes. This was followed by the addition of either anti-vinculin, a protein associated with focal adhesion kinase (FAK) primary antibody (1:100 in 1\% BSA/PBS, monoclonal antihuman raised in mouse [IgG1], Chemicon, CA, USA) for 1 hour at $37^{\circ} \mathrm{C}$ or anti-tubulin antibody to observe microtubules. The samples were then washed in $0.5 \%$ Tween $20 / \mathrm{PBS}$, and a secondary FITC-conjugated antibody (1:50 in 1\% BSA/PBS, monoclonal goat anti-mouse [IgG], Chemicon, CA, USA) was added for 1 hour at $37^{\circ} \mathrm{C}$ followed by washing. For $\mathrm{F}$-actin stain, rhodamine conjugated phalloidin was added for the duration of this incubation simultaneously (1:100 in $1 \% \mathrm{BSA} / \mathrm{PBS}$, Chemicon, CA, USA). After mounting the coverslip with antifading mounting medium (Vector H1200, Burlingame, CA, USA), samples were then viewed by laser confocal microscope (Leica Tcs, Mannheim, Germany).

\section{In vitro vasculogenesis assay}

In vitro vasculogenesis was assessed as the formation of capillary-like structures by the HUVECs. The experimental procedure followed the instructions provided with the tube formation kit (Chemicon, CA, USA). To observe the treatment effect of IONPs, HUVECs were exposed to the IONPs for 1 hour at iron concentrations of 0.1 and $1 \mathrm{mM}$. After IONPs exposure, $1 \times 10^{4}$ control cells and treated HUVECs were loaded on Matrigel and incubated at $37^{\circ} \mathrm{C}$, in growth medium containing low growth serum supplement (LSGS) for 8-12 hours to allow cellular network structures to fully develop. The formation of the tubular structures was monitored by calcein AM stain. Calcein-AM $10 \mu \mathrm{L}(1 \mathrm{nM})$ was added to each well and incubated for 15 minutes, before being washed with PBS 3 times and then being observed using a fluorescence microscope (Olympus IX71, Tokyo, Japan).

\section{HUVECs migration and invasion assay}

The migration assay was carried out with a modified Boyden chamber according to the kit instructions (Chemicon, CA, USA). Confluent HUVECs monolayers were cultured with non-growth factor-containing media for 24 hours 
and then supplemented with IONPs at the same iron concentrations for an extra 1 hour incubation before harvesting. Harvested cells were suspended at $106 / \mathrm{mL}$ in M200 with $1 \%$ serum, and 105 cells were seeded into upper chamber ( $8 \mu \mathrm{m}$ pore size of polycarbonate membrane). $10 \%$ serum medium was added into the lower chamber to stimulate the migration. Cells were allowed to migrate for 6-8 hours at $37^{\circ} \mathrm{C}$. Migration was terminated by flipping out the remaining cell suspension from the upper compartment, and cells were dislodged completely from the underside. The extent of cell migration was determined by CyQuant GR Dye staining and read with a fluorescence plate reader using a 480/520 nm filter set.

A cell invasion assay was performed in a 96-well invasion plate based on the Boyden chamber principle. The difference between the invasion and migration assay is a thin layer of extracellular matrix (ECM) coated on polycarbonate membrane as the intervening invasive barrier. The ECM layer occludes the membrane pores, blocking non-invasive cells from migrating through. Invasive cells, on the other hand, degrade the ECM, migrate through the ECM layer and cling to the bottom of the polycarbonate membrane. Briefly, the invasion assay was tested as in the migration assay. Prior to being seeded into the upper chamber in Medium 200 with $1 \%$ serum, cells were incubated with IONPs at 0.1 and $1 \mathrm{mM}$ for 1 hour after starving for 24 hours. The effect of IONPs on endothelial invasion was observed by their movement from the upper chamber (low serum in medium of $1 \%$ ) to the lower chamber (high serum in medium of $10 \%$ ). After 8 hours incubation, invading cells on the bottom of the insert membrane were dissociated from the membrane when incubated with cell detachment buffer, and subsequently lysed and detected by CyQuant GR dye.

\section{Statistical evaluation}

All results were expressed as mean \pm standard deviation (SD). Statistical comparisons were performed using Student's t-test (2-tailed) and two way ANOVA, a probability of $P$ value $<0.05$ was used to indicate a significant difference and $P$ value $<0.01$ to indicate a highly significant difference.

\section{Results}

\section{Magnetic nanoparticle characterization}

The TEM image of the magnetic nanoparticles was used to determine the shape, size and uniformity of the particles (Figures 1a and 1b). The figure shows that the particles were spherical shaped with an approximate core size of $38 \pm 8.14 \mathrm{~nm}$ for citrate-IONP and $31 \pm 6.58 \mathrm{~nm}$ for the dextran-IONP. The purified IONPs suspension was lyophilized and examined using FT-IR spectroscopy. As shown in Figure 1c, the $1700 \mathrm{~cm}^{-1}$ peak assignable to the $\mathrm{C}=\mathrm{O}$ vibration from the $\mathrm{COOH}$ group of citric-acid shifted to an intense band at about $1614 \mathrm{~cm}^{-1}$, revealing the binding of a citric acid radical to the magnetite surface. The lowintensity bands between $400 \mathrm{~cm}^{-1}$ and $600 \mathrm{~cm}^{-1}$ could be associated with the stretching and torsional vibration modes of the magnetite. In Figure 1d, there is an intense and broad band in the region of $3423 \mathrm{~cm}^{-1}$, which was assigned as the O-H stretching vibration, indicating the composite dextranIONP contained abundant of hydroxyl groups. (detailed FT-IR of iron oxide nanoparticles and coating material can be seen in Figures $\mathrm{S} 1-\mathrm{S} 3$ ).

\section{In vitro cell viability assay}

The viability assay of HUVECs showed that cell viability was affected in a concentration-dependent manner. The cytotoxicity of the nanoparticles increased with increasing iron concentration (Figure 2). The citrate-IONP has a significant toxic effect on HUVECs viability compared with the dextran-IONP (two way ANOVA, $P<0.05$ ). After 6 hours incubation the toxic effect of citrate-IONP became much stronger than the dextran-IONP (two way ANOVA, $P<0.01$ ). Overnight (24 hours) viability decreased less than $50 \%$ at iron concentrations of $1 \mathrm{mM}$ for both citrate-IONP and dextran-IONP (Figure S4).

\section{Prussian blue stain of intracellular IONPs}

Prussian blue stain (Figure 3) showed a strong uptake of IONPs after 1 hour incubation with different particles. The citrate-IONP and dextran-IONP particles appeared to be in clusters in the cell cytoplasm, partially around the nucleus and possibly located in endocytotic vesicles such as lysosomes. Additionally, cell detachment was observed after IONP incubation and there were less cells for $1 \mathrm{mM}$ IONP incubation than for $0.1 \mathrm{mM}$ IONP incubation.

\section{TEM of HUVECs after IONPs incubation}

As previously stated, iron oxide nanoparticles have been shown to be readily taken up by a variety of cells via an endocytotic mechanism. ${ }^{10-16}$ The internalization of citrateIONP and dextran-IONP by HUVECs at iron concentrations of $0.1 \mathrm{mM}$ and $1 \mathrm{mM}$ was verified using TEM (Figure 4). Figure 4 shows a large number of IONPs within the cytoplasm, particularly in numerous endocytotic vesicles such as lysosomes, accumulating in the perinuclear region within the cells (Figures $4 \mathrm{~b}$ and $4 \mathrm{c}$ ). The beginning of the uptake was a 

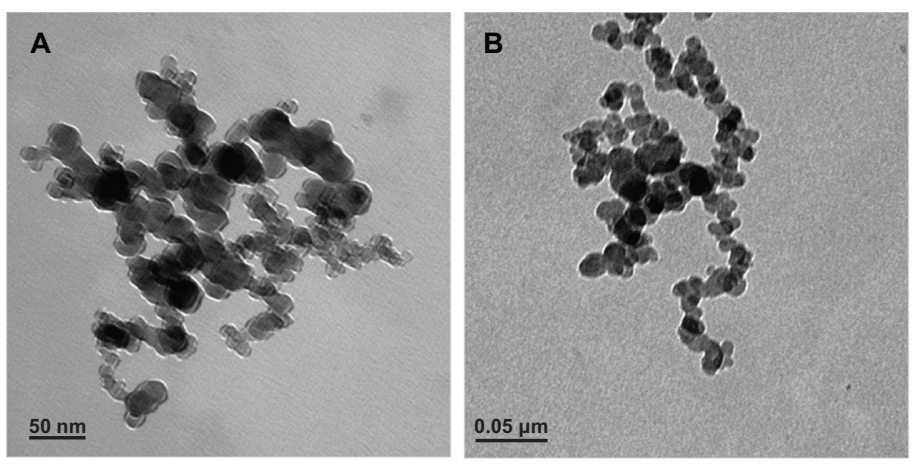

C

D
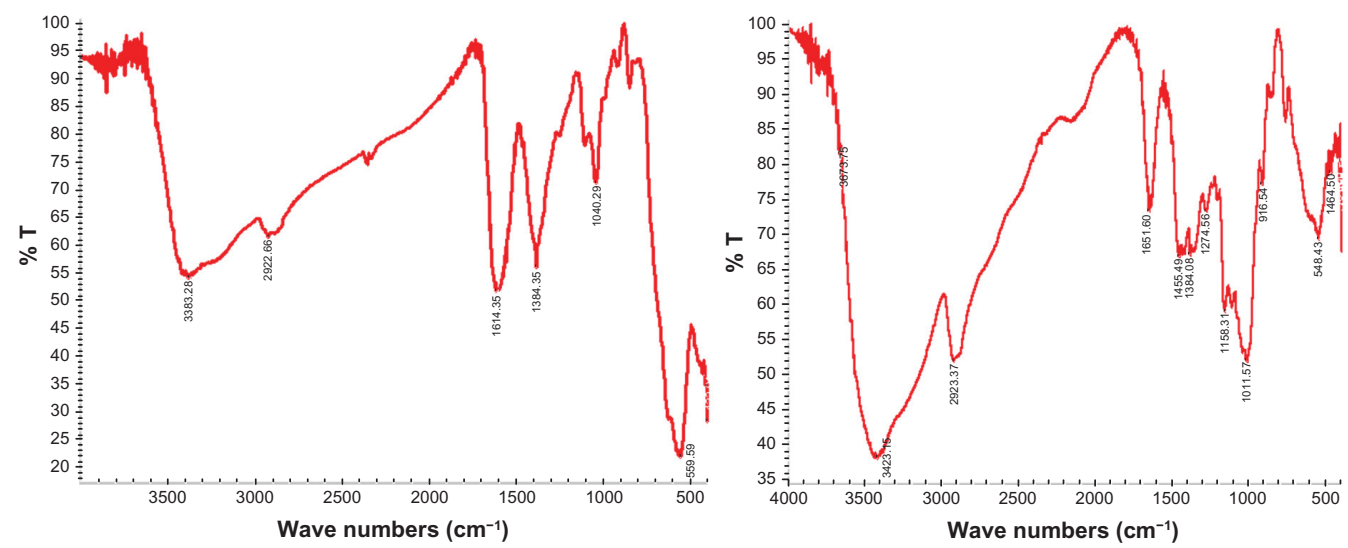

Figure I TEM images and FT-IR spectra of composite iron oxide nanoparticles.

Notes: (a, b) TEM of citrate and dextran-coated IONP; (c, d) FT-IR spectrum of citrate and dextran-coated IONP.

Abbreviations: IONP, iron oxide nanoparticles; TEM, transmission electron microscope; FT-IR, Fourier transformed infrared spectroscopy.

pit formation of the membrane and the lysosomes increased with higher iron concentrations. In addition, there were many vacuoles within the cytosol (Figures $4 \mathrm{~d}$ and $4 \mathrm{e}$ ) and abnormal dense filament matter (Figures $4 \mathrm{f}$ and $4 \mathrm{~g}$ ) appeared near the nucleus, indicating an active cell response to IONPs at the higher iron concentration of $1 \mathrm{mM}$.

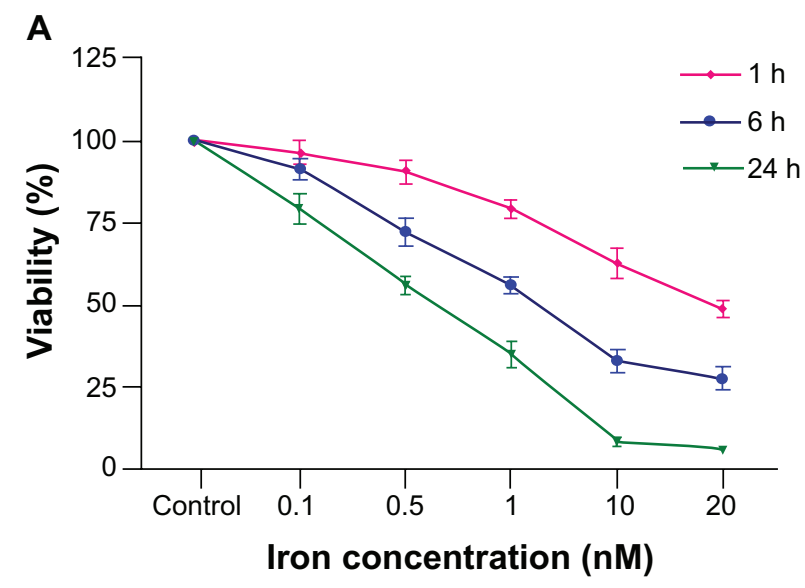

\section{Alteration of cytoskeleton and FAK}

In addition to HUVEC cell proliferation, the phenotype and cytoskeleton were also affected by increasing concentrations of IONPs. The changes in morphology and cytoskeletal structure of cells exposed to varying levels of IONPs were investigated using a fluorescence stain for vinculin

\section{B}

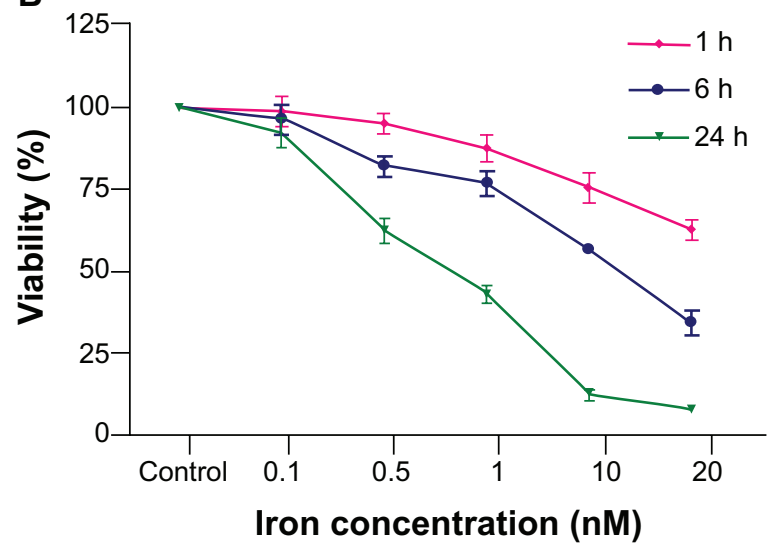

Figure 2 (a) Cell viability of citrate-IONP on HUVECs after I, 6 and 24 hours. (b) Cell viability of dextran-IONP on HUVECs after I, 6 and 24 hours. Notes: Percentage of viability of HUVECs was expressed relative to control cells $(n=3)$.

Abbreviations: HUVECs, human umbilical vein endothelial cells; IONP, iron oxide nanoparticles. 


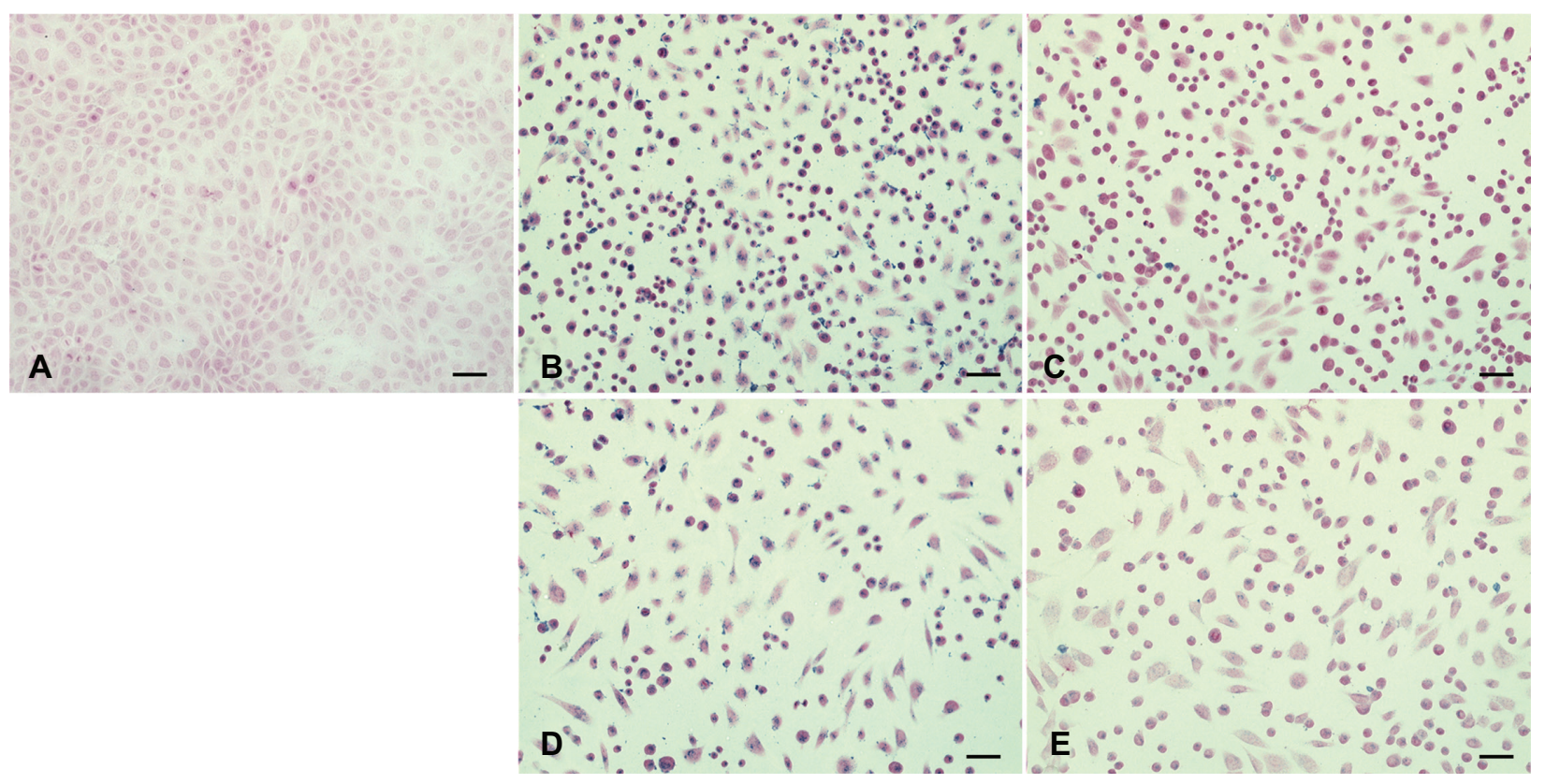

Figure 3 Prussian blue stained and nucleus fast red counterstained HUVECs incubated without or with different IONP samples. $(\times 200$ magnification).

Notes: (a) Control: without any particles; (b, d) with citrate-IONP; (c, e) with dextran-IONP; (b, c) cells were incubated with IONPs at iron concentration of 0.1 nM; (d, e) cells were incubated IONPs at iron concentration of I nM.

Abbreviations: HUVECs, human umbilical vein endothelial cells; IONP, iron oxide nanoparticles.

(FITC, green), F- actin (TRITC, red) and $\beta$-tubulin (FITC, green). Typically, untreated HUVEC cells are flat adherent to the substratum with clear vinculin and strong peripheral F-actin staining along the cell edge, indicative of cortical actin fibers (Figures 5a-5c). After 1 hour incubation with dextran-IONPs, cells exhibited small and round cell morphology, with F-actin appearing thinner and less organized within the main body (Figures 5e-5g). Furthermore, the cells incubated with citrate-IONP not only exhibited a smaller and more irregular cell morphology with vacuoles appearing within the cytoplasm, they also showed a flurry cell edge with diminished vinculin spots within the cells, indicating a reduction in stress fibers/FAK and the lamella actin network (Figures 5i-5k). The microtubular change caused by IONP internalization was further shown by $\beta$-tubulin stain. The microtubules formed a dense network almost equally distributed around the nucleus of the control cells (Figure 5d). Incubation with dextran-IONP resulted in the disruption of microtubule structures in the central and peripheral domain compared with control cells (Figure 5h). The effect of citrate-IONP exposure was demonstrated by a diffused tubulin stain and a shorter long axis, suggesting interference with polymerization and depolymerization. This result confirms a disorganization of the cytoskeleton due to the treatment with iron oxide nanoparticles.
This disorganization could cause a series of signal pathway disruptions, thus minimizing cell surface area and contact with the environment. Due to a severe detachment response of cells to particle incubation, cells were retracted and the fine structure could not be exhibited in a clear way.

\section{In vitro vasculogenesis assay}

Vascular endothelial cells will proliferate when cultured in the appropriate medium; however, they will not differentiate and form tube-like structures until they are presented with the appropriate cues, like collagen or fibronectin (Figure 6a)..$^{27,28}$ The formation of tubes by endothelial cells is a critical step in angiogenesis. The endothelial cell vasculogenesis assay was performed to examine the ability of the treated HUVEC cells to produce capillary-like tubular structures. The formation of the tubular structures was monitored by fluorescence microscopy with the calcein AM stain. For control cells, early cell junctions were observed between 1 and 2 hours after cell adhesion, the final geometrical network appearing prominently about 6 hours after cell adhesion. Cell structures then became slimmer with time (Figure 6b). However, for $0.1 \mathrm{mM}$ IONPs treated cells the kinetics of network formation was altered greatly, with little to no tube structure being found after seeding on the Matrigel, though the cells were still alive (Figures $6 \mathrm{c}$ and $6 \mathrm{~d}$ ). There were 

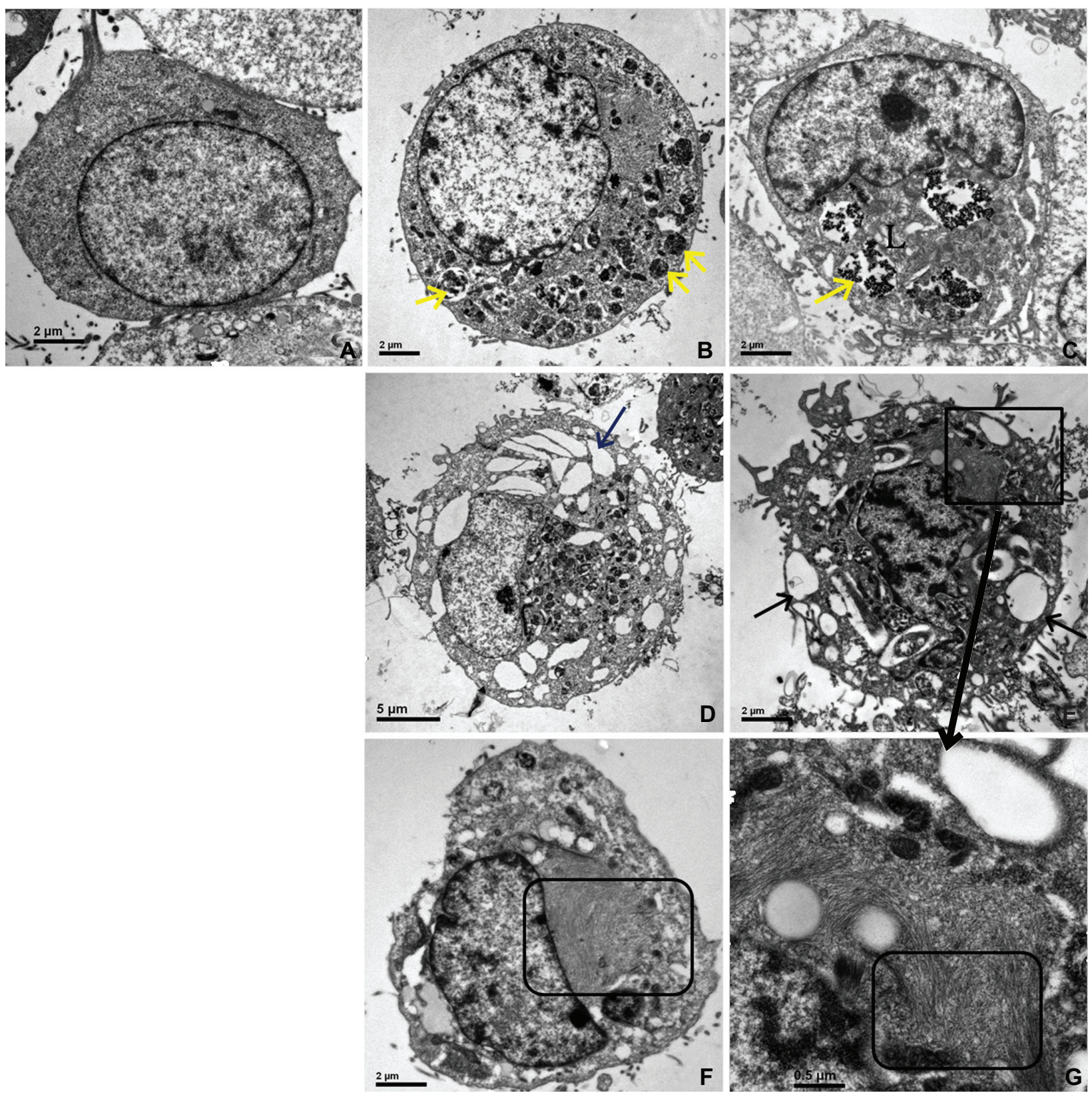

Figure 4 TEM of HUVECs incubated with IONPs for one hour, ( $\times 8000$ magnification).

Notes: (a) control cell (without incubation of any particles); (b, d, f) with citrate-IONP; (c, e, g) with dextran-IONP; (b, c) cells were incubated with IONPs at iron concentration of $0.1 \mathrm{nM} ;(\mathbf{d}-\mathbf{g})$ cells were incubated with IONPs at iron concentration of I nM; (b, c) Particles were taken up into lysosomes; (d, e) Many vacuoles could be found in cytoplasm; (f, g) Abnormal dense filament matter appeared adjacent to vacuoles (yellow arrow: IONPs, black arrow: vacuoles, rectangular: filaments, L: lysosome). Abbreviations: IONP, iron oxide nanoparticles; TEM, transmission electron microscope; HUVECs, human umbilical vein endothelial cells.

no tubular structures on the Matrigel after incubation with $1 \mathrm{mM}$ IONPs.

\section{HUVECs migration and invasion assay}

HUVEC migration in a modified Boyden chamber was a chemotactic model of migration representative of tumor-induced endothelial cell migration. Stimulation of HUVECs along a directional gradient of serum resulted in the migration to the underside of the membrane, and this was inhibited in a concentration-dependent manner by IONP. Addition of IONP significantly reduced the migration of HUVECs, the number of migrated cells more greatly inhibited by citrate-IONP at the concentration of $0.1 \mathrm{mM}$ (Figure 7). Due to the apparent toxic effect to cells, the inhibition capacity was not remarkably different at an iron concentration of $1 \mathrm{mM}$. 


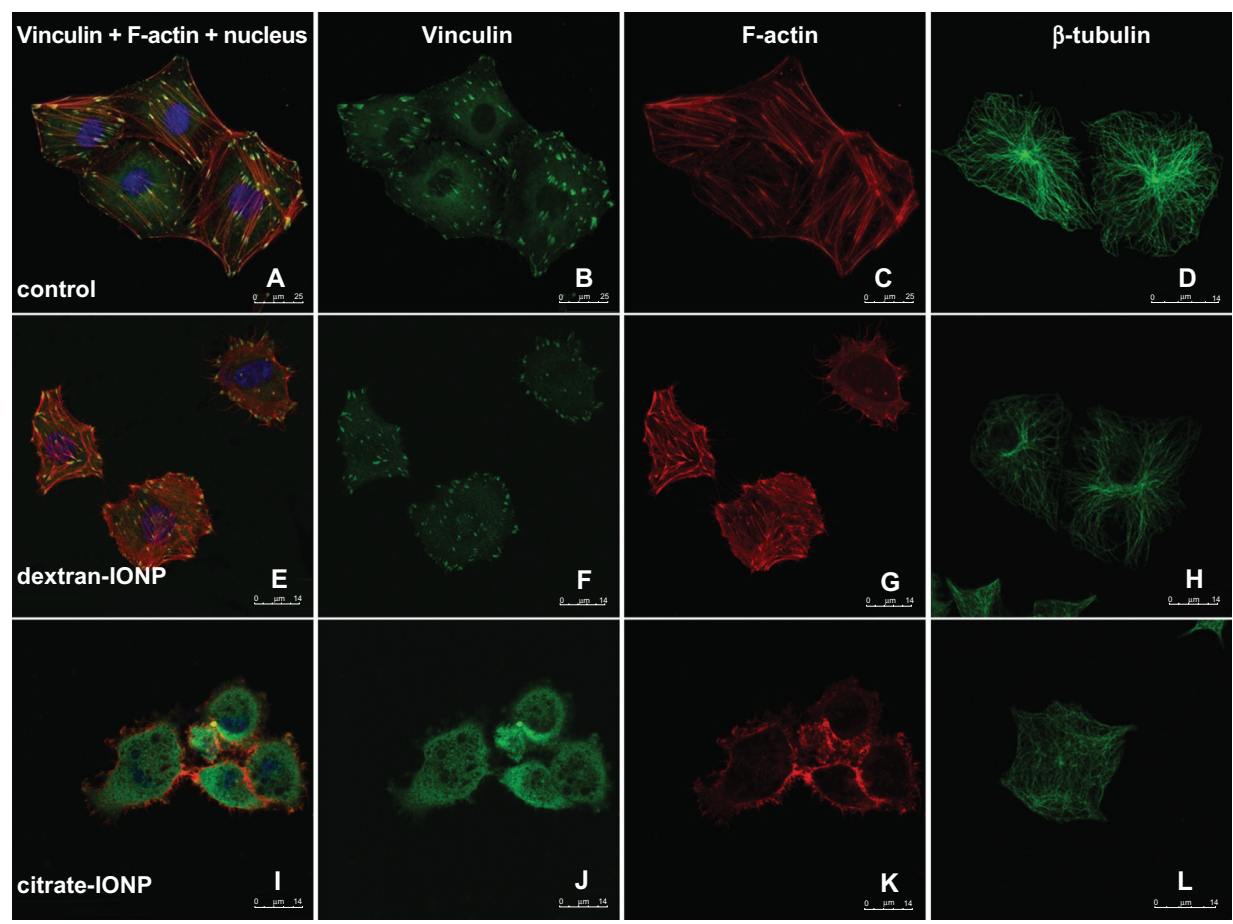

Figure 5 HUVECs were stained for $\mathrm{F}$-actin (red), vinculin (green), nucleus (blue) and $\beta$-tubulin (green) with or without IONPs incubation, $(\times I 3000$ magnification). Notes: (a-d) Untreated control cell; (e-h) One hour incubation with dextran-IONP at $0.1 \mathrm{mM}$; (i-l) One hour incubation with citrate-IONP at 0.1 mM. Abbreviations: HUVECs, human umbilical vein endothelial cells; IONP, iron oxide nanoparticles.
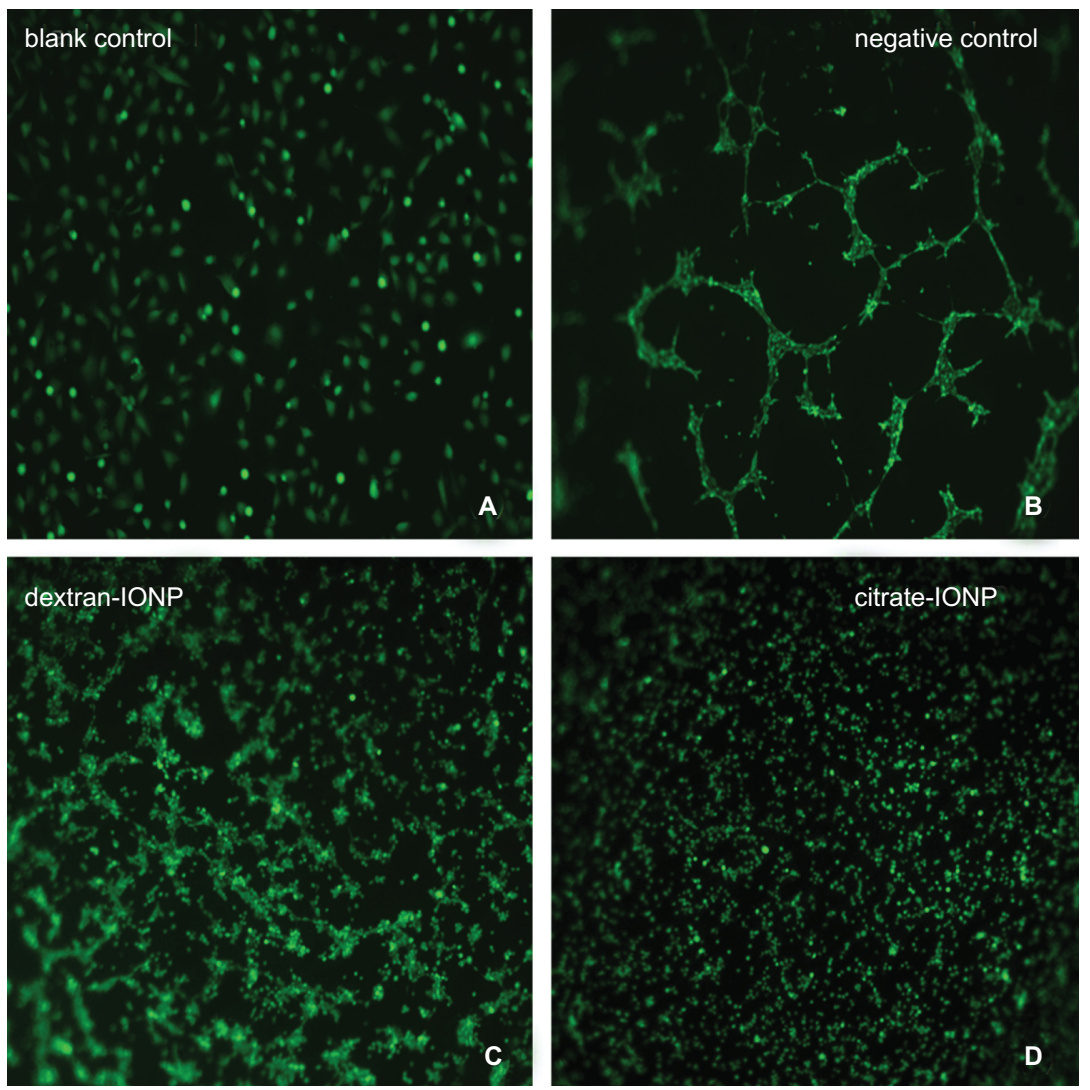

Figure 6 Vasculogenesis in vitro with HUVEC in different culture conditions (stained by calcein AM, $\times 100$ magnification)

Notes: (a) Cells were seeded on 96-well plate without Matrigel; (b) HUVECs which grew on Matrigel developed a geometrical network about 6 hours after cell adhesion; (c) dextran-IONP treated cells provided a partially poorly developed branch elongated shape compared with the untreated cells; (d) citrate-IONP treated cells demonstrated no tendency for vascular network formation.

Abbreviations: HUVECs, human umbilical vein endothelial cells; IONP, iron oxide nanoparticles. 


\section{Migration assay}

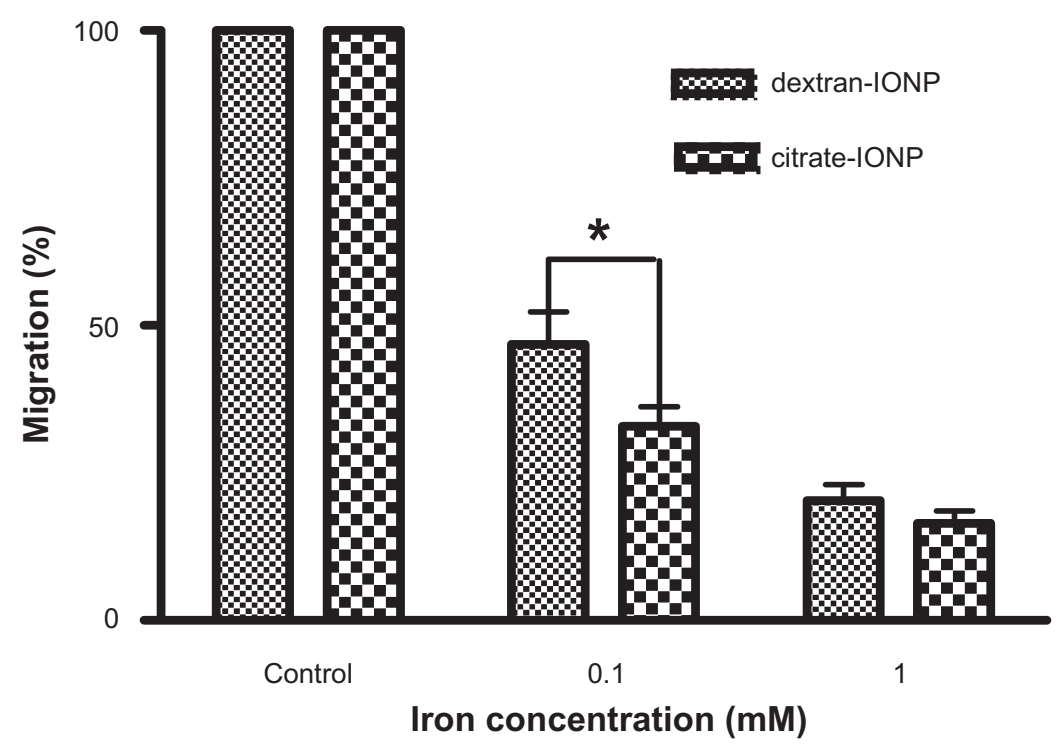

Figure 7 Migration assay of HUVECs under incubation with IONPs for I hour.

Notes: $(\bar{x} \pm S D, n=3) * P<0.05$. HUVECs were incubated with IONPs at different iron concentrations, and cell migration greatly decreased compared with control cells. Citrate-IONP reduced migration more than dextran-IONP at an iron concentration of $0.1 \mathrm{mM}$.

Abbreviations: HUVECs, human umbilical vein endothelial cells; IONP, iron oxide nanoparticles.

Since IONP inhibited cell adhesion and migration, we investigated the effect of IONP on the invasion of endothelial cells as well, using ECM invasion chambers. Invasion is a multistep process that involves cell adhesion, degradation of the matrix and migration of cells through the degraded matrix. Invasion of HUVEC cells was inhibited by IONPs, suggesting the involvement of multiple dysfunctions of HUVECs in this process. Citrate-IONP had a significantly negative effect in comparison with the dextran-IONP at all incubation concentrations (Figure 8).

\section{Invasion assay}

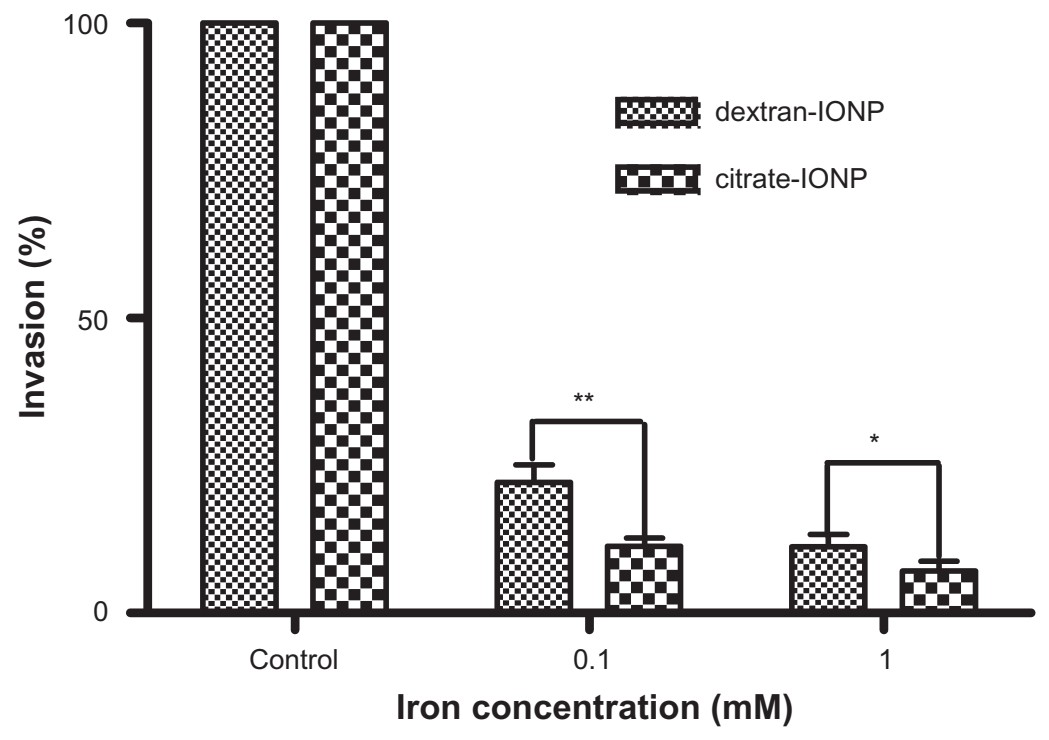

Figure 8 Invasion assay of HUVECs under incubation with IONPs for I hour.

Notes: $(\bar{x} \pm S D, \mathrm{n}=3) * P<0.05$, ** $P<0.01$. HUVEC invasion through the matrix was inhibited compared to control cells. Citrate-IONP had a stronger inhibition capacity than dextran-IONP $(P<0.05$, I mM; $P<0.01,0.1 \mathrm{mM})$.

Abbreviations: HUVECs, human umbilical vein endothelial cells; IONP, iron oxide nanoparticles. 


\section{Discussion}

After synthesis of the magnetic nanoparticles, surface modification is required to make the particles soluble. Surface modification also prevents the destabilization and aggregation of the particles. Dextran and citric acid are the most common biocompatible materials used for surface coating, having been used for clinical trials or diagnosis, eg, VSOP C184 and ferumoxides. ${ }^{22,23}$ The endothelial cell is an important target in the study of arteriosclerosis and anti-angiogenesis therapy. We chose dextran and citric acid as coating materials to test the nanotoxic effects on HUVECs in order to understand the possible interaction between coated particles and endothelial cells. In our research, HUVECs can internalize large amounts of both citrate-IONP and dextran-IONP.

\section{Acute cytotoxicity}

Internalization after exposure to IONPs drastically affected HUVEC growth and proliferation. In our findings significant toxic effects were seen above the concentration of $1 \mathrm{mM}$ since the HUVEC viability rate decreased below $50 \%$ after overnight exposure of IONPs. In the present case, the decease of cell proliferation is difficult to explain. One possible reason might be free radical generation through iron-catalyzed HaberWeiss reactions. ${ }^{29,30}$ The Haber-Weiss reaction, which makes use of Fenton chemistry, is now considered to be the major mechanism generating highly reactive hydroxyl radicals in biological systems. The Fenton reaction becomes noticeable at higher intracellular concentrations of iron salts..$^{29}$ The free radicals could damage DNA, cell membrane, cytoskeleton and ECM, and also mediate signal transduction pathways directly or indirectly though bioactive mediators. ${ }^{29,31}$ Karlsson and colleagues suggested that IONP can cause low levels of toxicity due to the potency in causing oxidative DNA lesions in cultured A549 cells (the human lung epithelial cell line). ${ }^{32}$ Citrate-coated IONP had much more capacity than dextranIONP to inhibit cell migration/invasion and proliferation, and rapid degradation of the particle shell might account for greater exposure of ferric cores, which contributes to citrateIONP's greater toxic effect on HUVECs.

Another possible explanation for the toxic effects of IONP internalization is the apparent formation and migration of the IONPs containing endosomes/autophagosome to the proximal perinuclear region of the HUVECs. In cell biology, autophagy, or autophagocytosis, is a catabolic process involving the degradation of a cell's own components through the lysosomal machinery when induced by specific drugs or starving. It has been proposed that autophagy resulting in the total destruction of the cell is one of several types of programmed cell death. Observations that cells possessing autophagic features in areas undergoing programmed cell death have led to the coining of the phrase autophagic cell death (also known as cytoplasmic cell death or type II cell death). ${ }^{33-35}$ The most well-known mechanism of autophagy involves the formation of a membrane around a targeted region of the cell, separating the contents from the rest of the cytoplasm. This was confirmed by many membrane structured vacuoles in the cytoplasm in the TEM images and under fluorescent staining (Figure 4 and Figure 5). It might be that the autophagocytosis under exposure to IONPs partially caused cell morphology changes and final cell death (Supplementary Figures S5 and S6).

\section{Alteration of the cytoskeleton and cell response to biological cues}

From the results of cytoskeleton organization studies, we observed that both types of nanoparticles induced great changes in cytoskeleton organization and cell morphology, like cell retraction, rounding, disruption of F-actin and microtubules. Moreover, the F-actin microfilament and focal adhesion complex diminished under the treatment of citrateIONP, suggesting that coating material is closely related to the cell response to IONPs. Additionally, there were massive dense filament matters adjacent to the nucleus and vacuoles in the cytoplasm in TEM (Figures $4 \mathrm{f}$ and $4 \mathrm{~g}$ ). The explanation for the phenomenon is that there is a link between cytoskeleton organization and the endocytosis process. ${ }^{36}$ The relationship between the two processes might involve interactions between distinct protein complexes, depending on the nature of the particles being internalized.

Cell migration and invasion are multistep complex processes, requiring coordinated activities of cytoskeleton, membrane and adhesion systems. ${ }^{37-41}$ FAK-enhanced external signals to actin are necessary to mediate the survival of anchorage-dependent cells and critical for efficient cell mobility in response to external stimulation. ${ }^{38,41}$ From our results, FAK decreased/diminished after IONPs incubation and the tight relationship between stress fibers and FAK disappeared (Figure 5). Those changes in the cytoskeleton assembly and FAK impeded cell signal transduction and impaired cell mobility. The eventual cell detachment also induced apoptosis by anoikis. ${ }^{42}$ Recent findings show that FAK contribute to the secretion of matrix-metalloproteinases and represent an important checkpoint in coordinating the dynamic processes of cell motility and extracellular matrix remodeling during cell invasion. ${ }^{43-45}$ This would be a substantial theory to explain why IONPs had stronger inhibition 
on cell invasion than migration because the IONPs caused failure of ECM degradation, the most important step in the invasion process.

Vasculogenesis, the growth of the primary vascular network from initially dispersed endothelial cells, is the first step in the development of the circulatory system in vertebrates. In vitro culture of HUVECs in Matrigel $^{\mathrm{TM}}$ is a popular experimental model of capillary development. Matrigel is an extracellular matrix product obtained from murine tumors. ${ }^{46-48}$ It is widely assumed that the adhesion-based activities are the key points for vasculogenesis. ${ }^{47}$ After sensing the extracellular proteins and growth factors in the gel, HUVECs are stimulated to elongate and form networks (Figure 6b) resembling vascular networks in vivo, where cords of endothelial cells surround empty lacunae. After incubation with of IONPs, even at the lowest tested concentration, incubation appeared to affect cytoskeletal structure and inhibit maturation and the differentiation of HUVECs to form vascular structures (Figures $6 \mathrm{c}$ and $6 \mathrm{~d}$ ). The disruption of F-actin, FAK and tubulin caused by IONP incubation might contribute to the cell detachment and the failure of differentiation, since all these processes need the coordination of the cytoskeleton to complete complicated and sophisticated signal communication, which are cell adhesion, mobility and elongation.

\section{Potential indication for cell labeling and cancer therapy}

Magnetic iron oxide nanoparticles have been widely used to label stem cells or progenitor cells for cell tracking or targeted imaging in myocardial infarction or atherosclerosis. However, there has been little reported concern about cell behavior and function change after IONP labeling. In our experiment, cytoskeleton and cell motility capacity were greatly affected after IONP incubation at low iron concentration $(0.1 \mathrm{mM})$, although cell viability did not significantly decrease. These findings should be taken into account when researchers observe cell motility or adhesion related parameters. A single cell viability assay is not enough to evaluate a nanotoxic effect and might underestimate cell-particle interaction if IONPs biologic effects are neglected. In our experiment, we compared citrate coating with dextran coating, quantitatively and qualitatively, considering cell proliferation, cytoskeleton and other related functional capacities. The results confirmed the view that an interaction might be cell type specific, and more attention should be given to the influence of particle surface modification and surface charge..$^{9-12}$

Angiogenesis is a fundamental step in the transition of tumors from a dormant state to a malignant one and is crucial for tumor growth and metastasis; which requires an abundance of oxygen and nutrients to proliferate. Antiangiogenic therapies affect vascular structure and function in different ways to cut off the nutrient supply and cause the tumor to regress. IONPs have been used as a carrier to deliver the toxic drug (eg, doxorubicin) to target sites by applying an external magnet, and IONPs have been injected into tumor vascular systems as a hyperthermia agent. ${ }^{3,20}$ In our experiment, we revealed that low concentrations of IONPs effectively induce a decrease of HUVECs viability and inhibited HUVECs differentiation and migration/invasion. This might have the potential to be used as an optional cost-effective alternative chemotherapy by transcatheter arterial embolization and hyperthermia without complex drug design.

\section{Conclusion}

In summary, this study has demonstrated that exposure to IONPs results in a dose-dependent decrease of HUVECs viability and inhibits their differentiation on Matrigel and migration/ invasion to stimulus factors. The results confirm that the toxicity of IONPs affect the biocompatibility and biosafety for in vivo or in vitro experiments. On the other hand, a toxic effect might be applied to tumor therapy, with measures to deal with the safety and feasibility. Although it was found that cytoskeleton organization and related cell function were interfered with, further studies into the physiochemical basis involved in cell phagocytosis and transportation of IONPs may help to elucidate the mechanisms of this interference to a greater degree.

\section{Acknowledgments}

We are sincerely grateful to Dr Yesen Li for his excellent assistance in nanoparticle preparations. We also thank Dr Zhongcai Chen for his kind help with cell experiments and fluorescent staining. Technical support from EmoryGeorgia Tech Nanotechnology Center for Personalized and Predictive Oncology and Zhejiang California Nanosystems Institute is acknowledged.

This research was supported by the Chinese National Programs for High Technology Research and Development (Grant No. 2006AA02Z485), Specific Prevention and Control Technology for Major Disease (Grant No. 2008C13027-2), Natural Science Foundation of Zhejiang Province (Grant No. J20060714), Special Foundation for Young Scientists of Zhejiang Province (Grant No. 2009QN009).

\section{Disclosures}

The authors have no conflicts of interest that are directly relevant to the content of this work. 


\section{References}

1. Islam T, Harisinghani MG. Overview of nanoparticle use in cancer imaging. Cancer Biomark. 2009;5(2):61-67.

2. Xie J, Huang J, Li X, et al. Iron oxide nanoparticle platform for biomedical applications. Curr Med Chem. 2009;16(10):1278-1294.

3. Sajja HK, East MP, Mao H, et al. Development of multifunctional nanoparticles for targeted drug delivery and noninvasive imaging of therapeutic effect. Curr Drug Discov Technol. 2009;6(1):43-51.

4. Gupta AK, Naregalkar RR, Vaidya VD, et al. Recent advances on surface engineering of magnetic iron oxide nanoparticles and their biomedical applications. Nanomed. 2007;2(1):23-39.

5. Barry SE. Challenges in the development of magnetic particles for therapeutic applications. Int J Hyperthermia. 2008;24(6):451-466.

6. Hadjipanayis CG, Bonder MJ, Balakrishnan S, et al. Metallic iron nanoparticles for MRI contrast enhancement and local hyperthermia. Small. 2008;4(11):1925-1929.

7. Le Renard PE, Buchegger F, Petri-Fink A, et al. Local moderate magnetically induced hyperthermia using an implant formed in situ in a mouse tumor model. Int J Hyperthermia. 2009;25(3):229-239.

8. Gupta AK, Gupta M. Synthesis and surface engineering of iron oxide nanoparticles for biomedical applications. Biomaterials. 2005;26(18): 3995-4021.

9. Ito A, Shinkai M, Honda $\mathrm{H}$, et al. Medical application of functionalized magnetic nanoparticles. J Biosci Bioeng. 2005;100(1):1-11.

10. Berry CC, Wells S, Charles S, et al. Dextran and albumin derivatised iron oxide nanoparticles: influence on fibroblasts in vitro. Biomaterials. 2003;24(25):4551-4557.

11. Mahmoudi M, Simchi A, Milani AS, et al. Cell toxicity of superparamagnetic iron oxide nanoparticles. J Colloid Interface Sci. 2009;336(2):510-518.

12. Simoni AR, Garcia MP, Azevedo RB, et al. Evaluation of the binding properties of maghemite nanoparticle surface-coated with meso-2-3dimercaptosuccinic acid to serum albumin. J Nanosci Nanotechnol. 2008;8(11):5813-5817.

13. Jaffer FA, Nahrendorf M, Sosnovik D, et al. Cellular imaging of inflammation in atherosclerosis using magnetofluorescent nanomaterials. $\mathrm{Mol}$ Imaging. 2006;5(2):85-92.

14. Sosnovik DE. Molecular imaging in cardiovascular magnetic resonance imaging: current perspective and future potential. Top Magn Reson Imaging. 2008;19(1):59-68.

15. Pisanic TR 2nd, Blackwell JD, Shubayev VI, et al. Nanotoxicity of iron oxide nanoparticle internalization in growing neurons. Biomaterials. 2007;28(16):2572-2581.

16. de Freitas ER, Soares PR, Santos Rde P, et al. In vitro biological activities of anionic gamma- $\mathrm{Fe}_{2} \mathrm{O}_{3}$ nanoparticles on human melanoma cells. J Nanosci Nanotechnol. 2008;8(5):2385-2391.

17. Liu J, Chao B. MRI-based visualization of iron-labeled CD133+ human endothelial progenitor cells. Biol Trace Elem Res. 2008;126(1-3):83-91.

18. Arbab AS, Janic B, Knight RA, et al. Detection of migration of locally implanted AC133+ stem cells by cellular magnetic resonance imaging with histological findings. FASEB J. 2008;22(9):3234-3246.

19. Wilhelm C, Bal L, Smirnov P, et al. Magnetic control of vascular network formation with magnetically labeled endothelial progenitor cells. Biomaterials. 2007;28(26):3797-3806.

20. Pardoe H, Clark PR, St Pierre TG, et al. A magnetic resonance imaging based method for measurement of tissue iron concentration in liver arterially embolized with ferrimagnetic particles designed for magnetic hyperthermia treatment of tumors. Magn Reson Imaging. 2003;21(5): 483-488.

21. Baalousha M. Aggregation and disaggregation of iron oxide nanoparticles: Influence of particle concentration, $\mathrm{pH}$ and natural organic matter. Sci Total Environ. 2009;407(6):2093-2101.

22. Budde MD, Frank JA. Magnetic tagging of therapeutic cells for MRI. J Nucl Med. 2009;50(2):171-174.

23. Schellenberger E, Rudloff F, Warmuth C, et al. Protease-specific nanosensors for magnetic resonance imaging. Bioconjug Chem. 2008;19(12):2440-2445.
24. Pieters R, Loonen AH, Huismans DR, et al. In vitro drug sensitivity of cells from children with leukemia using the MTT assay with improved culture conditions. Blood. 1990;76(11):2327-2336.

25. Mahmoudi M, SimchiA, Milani AS, et al. Cell toxicity of superparamagnetic iron oxide nanoparticles. J Colloid Interface Sci. 2009;336(2):510-518.

26. Kiessling F, Huppert J, Zhang C, et al. RGD-labeled USPIO inhibits adhesion and endocytotic activity of alpha $\mathrm{v}$ beta3-integrin-expressing glioma cells and only accumulates in the vascular tumor compartment. Radiology. 2009;253(2):462-469.

27. Akhtar N, Dickerson EB, Auerbach R. The sponge/Matrigel angiogenesis assay. Angiogenesis. 2002;5(1-2):75-80.

28. Auerbach R, Lewis R, Shinners B, et al. Angiogenesis assays: a critical overview. Clin Chem. 2003;49(1):32-40.

29. Kehrer JP. The Haber-Weiss reaction and mechanisms of toxicity. Toxicology. 2000;149(1):43-50.

30. Apopa PL, Qian Y, Shao R, et al. Iron oxide nanoparticles induce human microvascular endothelial cell permeability through reactive oxygen species production and microtubule remodeling. Part Fibre Toxicol. 2009;6:1.

31. Videla LA, Fernández V, Tapia G, et al. Oxidative stress-mediated hepatotoxicity of iron and copper: role of Kupffer cells. Biometals. 2003;16(1):103-111.

32. Karlsson HL, Gustafsson J, Cronholm P, et al. Size-dependent toxicity of metal oxide particles-a comparison between nano- and micrometer size. Toxicol Lett. 2009;188(2):112-118.

33. Gozuacik D, Kimchi A. Autophagy as a cell death and tumor suppressor mechanism. Oncogene. 2004;23(16):2891-2906.

34. Berry DL, Baehrecke EH. Autophagy functions in programmed cell death. Autophagy. 2008;4(3):359-360.

35. Bursch W. Multiple cell death programs: Charon's lifts to Hades. FEMS Yeast Res. 2004;5(2):101-110.

36. Qualmann B, Kessels MM, Kelly RB. Molecular links between endocytosis and the actin cytoskeleton. J Cell Biol. 2000;150(5):F111-F116.

37. Kirchhausen T. Imaging endocytic clathrin structures in living cells. Trends Cell Biol. 2009;19(11):596-605.

38. Schaub S, Bohnet S, Laurent VM, et al. Comparative maps of motion and assembly of filamentous actin and myosin II in migrating cells. Mol Biol Cell. 2007;18(10):3723-3732.

39. Miles FL, Pruitt FL, van Golen KL, et al. Stepping out of the flow: capillary extravasation in cancer metastasis. Clin Exp Metastasis. 2008;25(4):305-324.

40. Kirfel G, Rigort A, Borm B, et al. Cell migration: mechanisms of rear detachment and the formation of migration tracks. Eur J Cell Biol. 2004;83(11-12):717-724.

41. Pollard TD, Cooper JA. Actin, a central player in cell shape and movement. Science. 2009;326(5957):1208-1212.

42. Chiarugi P, Giannoni E. Anoikis: a necessary death program for anchorage-dependent cells. Biochem Pharmacol. 2008;76(11):1352-1364.

43. Hauck CR, Hsia DA, Schlaepfer DD. The focal adhesion kinase-a regulator of cell migration and invasion. IUBMB Life. 2002;53(2):115-119.

44. Oliva IB, Coelho RM, Barcellos GG, et al. Effect of RGD-disintegrins on melanoma cell growth and metastasis: involvement of the actin cytoskeleton, FAK and c-Fos. Toxicon. 2007;50(8):1053-1063.

45. Echarri A, Muriel O, Del Pozo MA. Intracellular trafficking of raft/ caveolae domains: insights from integrin signaling. Semin Cell Dev Biol. 2007;18(5):627-637.

46. Lamalice L, Le Boeuf F, Huot J. Endothelial cell migration during angiogenesis. Circ Res. 2007;100:782-794.

47. Nakatsu MN, Sainson RC, Aoto JN, et al. Angiogenic sprouting and capillary lumen formation modeled by human umbilical vein endothelial cells (HUVEC) in fibrin gels: the role of fibroblasts and Angiopoietin-1. Microvasc Res. 2003;66(2):102-112.

48. Goodwin AM. In vitro assays of angiogenesis for assessment of angiogenic and anti-angiogenic agents. Microvasc Res. 2007;74(2-3):172-183. 


\section{Supplementary data}

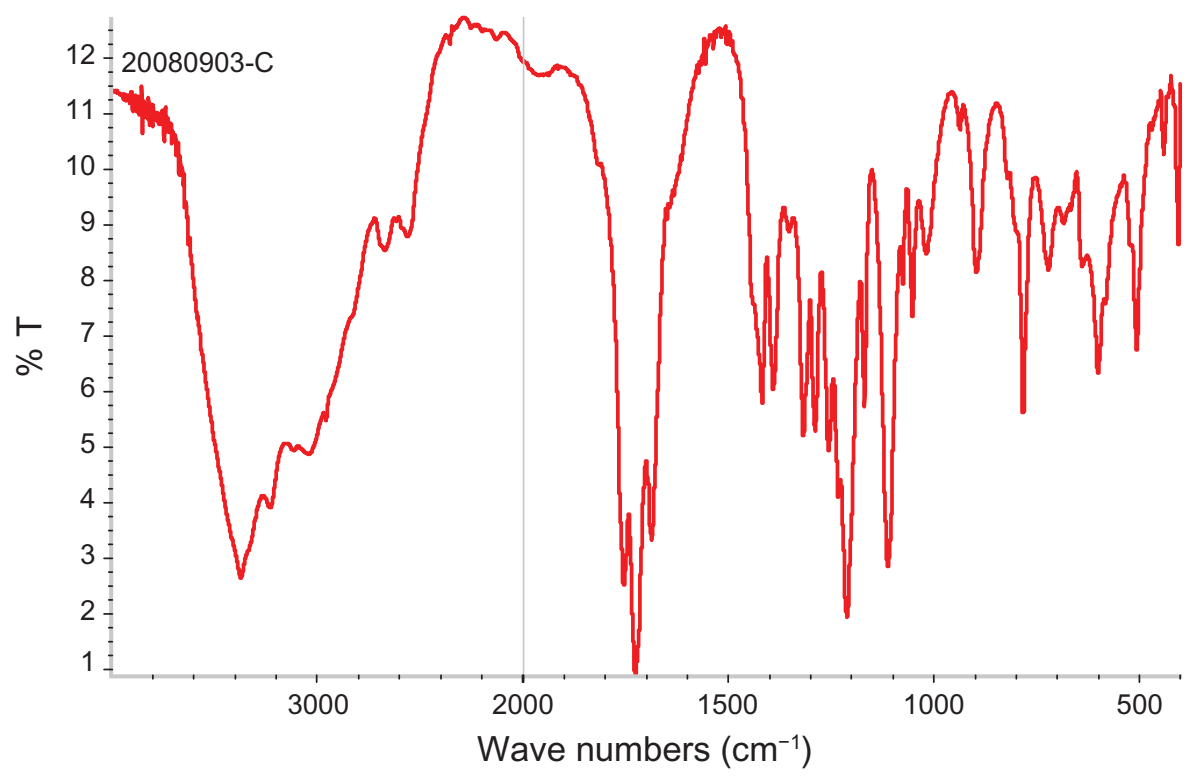

Figure SI FT-IR spectra of citric acid.

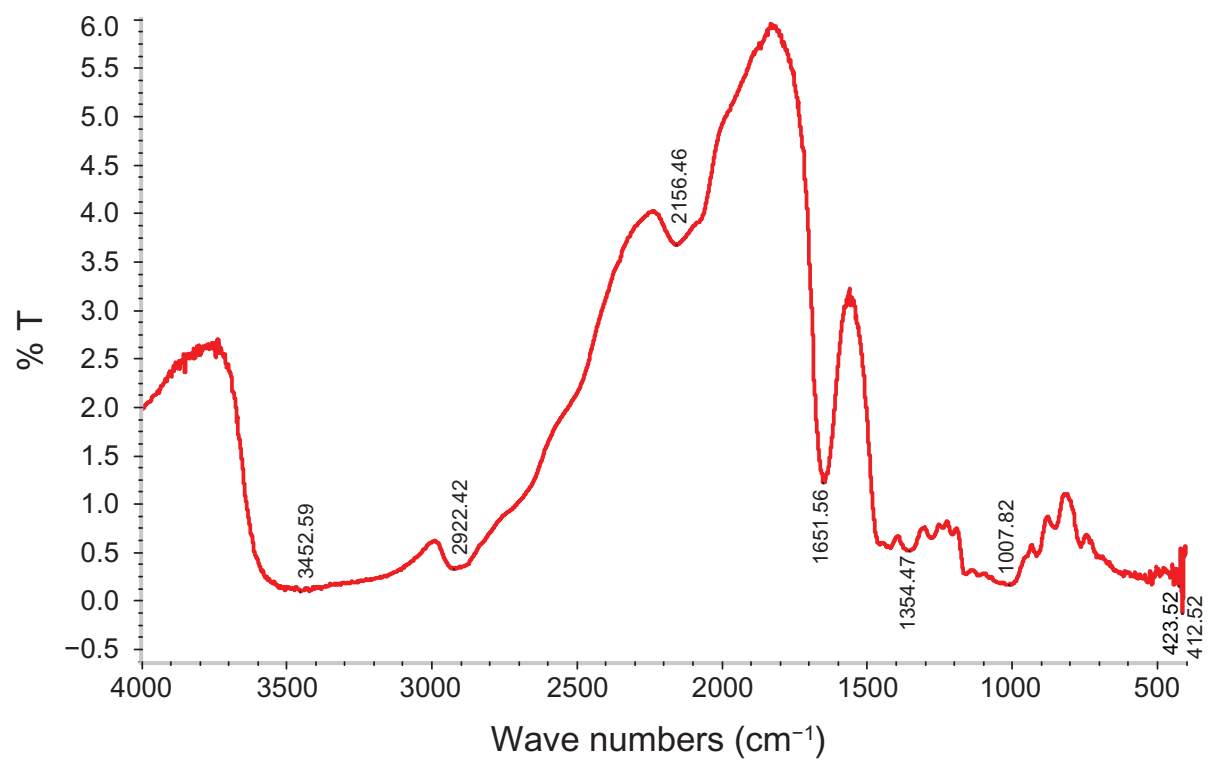

Figure S2 FT-IR spectra of dextran. 


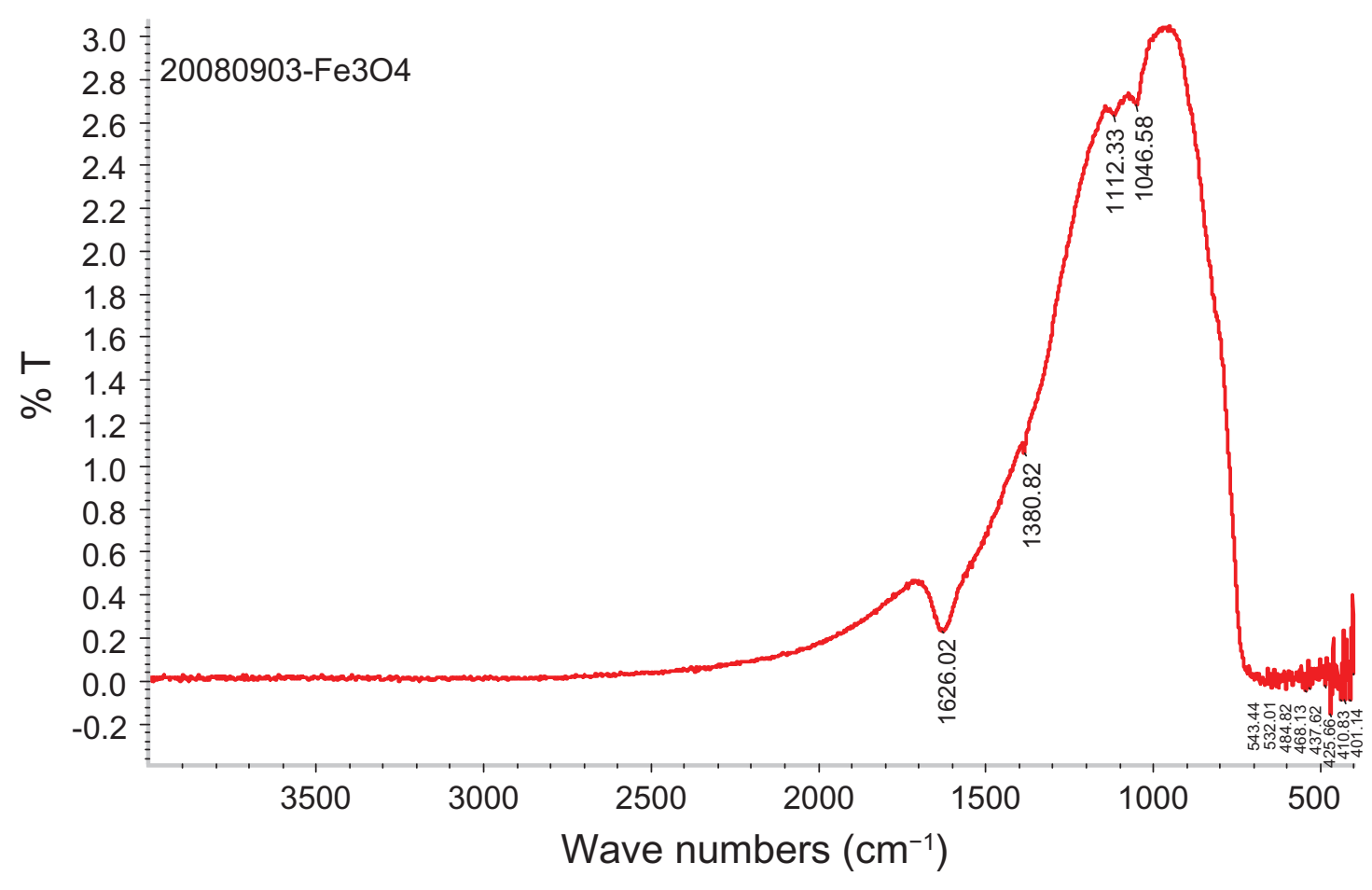

Figure S3 FT-IR spectra of bare iron oxide particles.
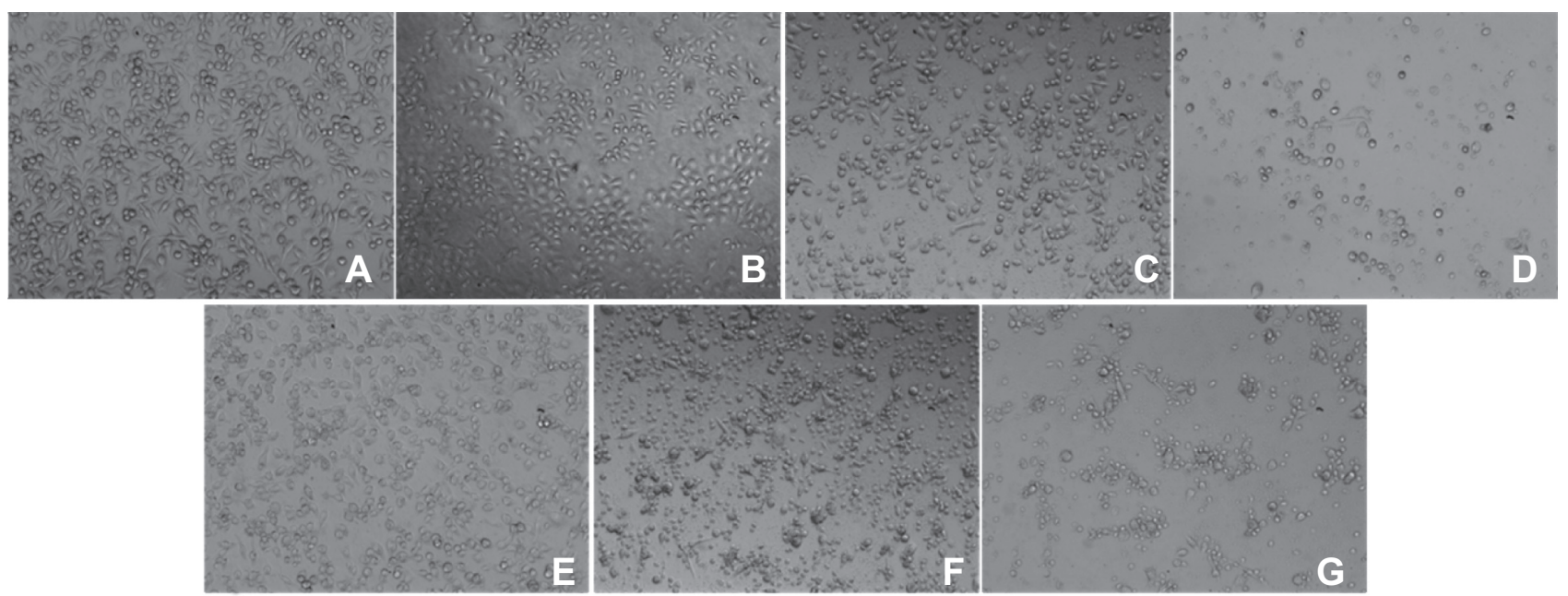

Figure S4 Optical microscopy of HUVECs incubated without or with different IONPs for $24 \mathrm{~h}$. (a) control cell without any particles; (b-d) cells were incubated with citrateIONP at iron concentration of $0.1, I$ and $10 \mathrm{nM} ;(\mathbf{e}-\mathrm{g})$ cells were incubated with dextran-IONP at iron concentration of 0.1 , I and I0 $\mathrm{nM}$. 

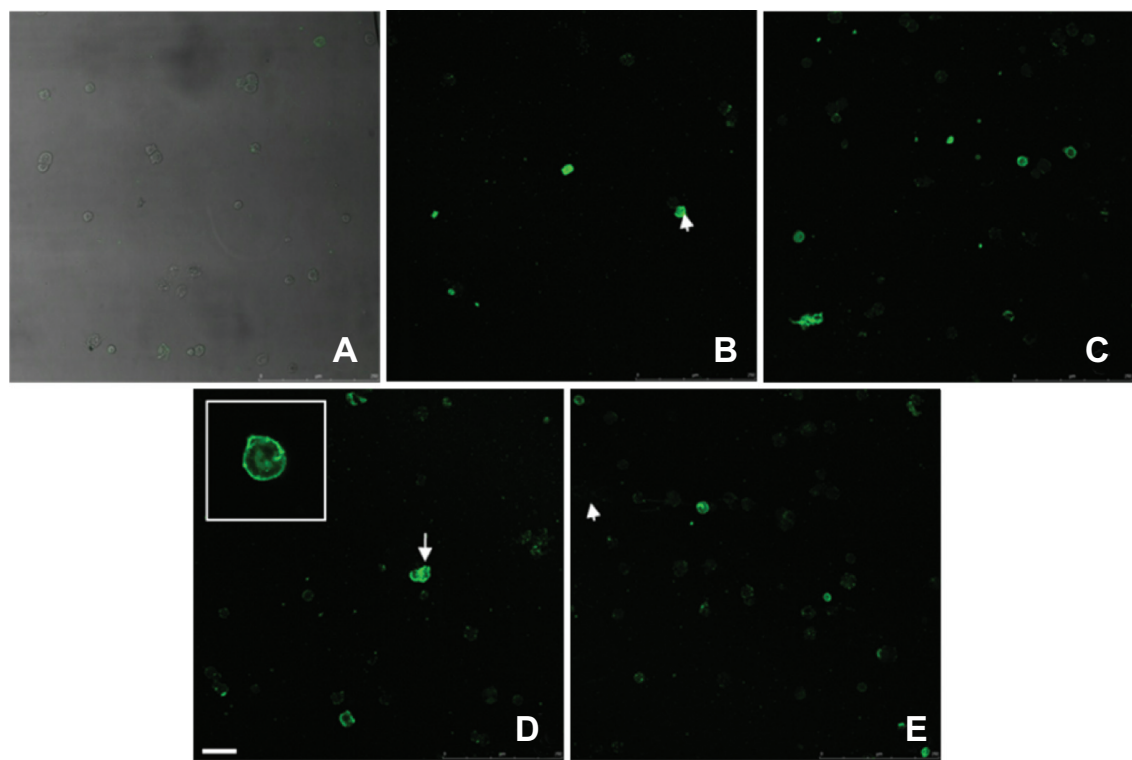

Figure S5 Annexin V kit fluorescent staining of HUVECs incubated without or with different IONPs for $6 \mathrm{~h}$. (a) control cells without any particles; (b, d) with citrate-IONP; (d, e) with dextran-IONP; (b, c) cells were incubated with IONPs at iron concentrations of $0.1 \mathrm{nM}$. cells were incubated with IONPs at iron concentration of I nM. Arrows denote possible apoptotic cells. Bar $100 \mu \mathrm{m}$.

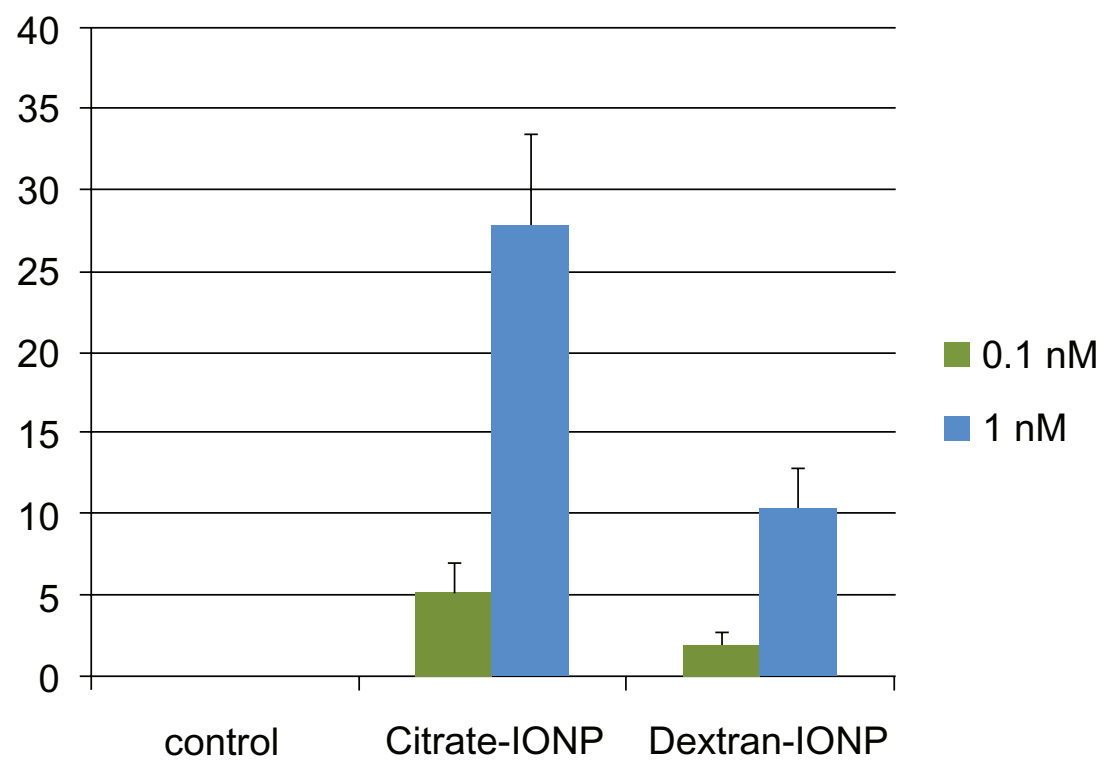

Figure S6 The percentage of apoptotic cells were counted and expressed graphically after $6 \mathrm{~h}$ exposure to IONPs.

International Journal of Nanomedicine

\section{Publish your work in this journal}

The International Journal of Nanomedicine is an international, peerreviewed journal focusing on the application of nanotechnology in diagnostics, therapeutics, and drug delivery systems throughou the biomedical field. This journal is indexed on PubMed Central, MedLine, CAS, SciSearch ${ }^{\circledR}$, Current Contents ${ }^{\circledR} /$ Clinical Medicine,

\section{Dovepress}

Journal Citation Reports/Science Edition, EMBase, Scopus and the Elsevier Bibliographic databases. The manuscript management system is completely online and includes a very quick and fair peer-review system, which is all easy to use. Visit http://www.dovepress.com/ testimonials.php to read real quotes from published authors.

\footnotetext{
Submit your manuscript here: http://www.dovepress.com/international-journal-of-nanomedicine-journal
} 